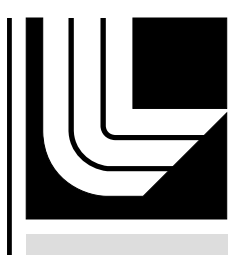

LAW RENCE LIVERMORE N A TIO N A L LABORATORY

\title{
UCRL-TR-219096
}

\section{Overview of an Urban Canopy Parameterization in COAMPS}

M. J. Leach, H.-N. S. Chin

February 17, 2006 
This document was prepared as an account of work sponsored by an agency of the United States Government. Neither the United States Government nor the University of California nor any of their employees, makes any warranty, express or implied, or assumes any legal liability or responsibility for the accuracy, completeness, or usefulness of any information, apparatus, product, or process disclosed, or represents that its use would not infringe privately owned rights. Reference herein to any specific commercial product, process, or service by trade name, trademark, manufacturer, or otherwise, does not necessarily constitute or imply its endorsement, recommendation, or favoring by the United States Government or the University of California. The views and opinions of authors expressed herein do not necessarily state or reflect those of the United States Government or the University of California, and shall not be used for advertising or product endorsement purposes.

This work was performed under the auspices of the U.S. Department of Energy by University of California, Lawrence Livermore National Laboratory under Contract W-7405-Eng-48. 


\title{
Overview of an Urban Canopy Parameterization in COAMPS
}

\author{
Martin J. Leach and Hung-Neng S. Chin \\ Energy and Environment Directorate \\ Lawrence Livermore National Laboratory \\ Livermore, CA 94551
}

\section{COAMPS Model Description}

The Coupled Atmosphere/Ocean Mesoscale Prediction System (COAMPS) model (Hodur, 1997) was developed at the Naval Research Laboratory. COAMPS has been used at resolutions as small as $2 \mathrm{~km}$ to study the role of complex topography in generating mesoscale circulation (Doyle, 1997). The model has been adapted for use in the Atmospheric Science Division at LLNL for both research and operational use. The model is a fully, non-hydrostatic model with several options for turbulence parameterization, cloud processes and radiative transfer. We have recently modified the COAMPS code to include building and other urban surfaces effects in the mesoscale model by incorporating an urban canopy parameterization (UCP) (Chin et al., 2005). This UCP is a modification of the original parameterization of (Brown and Williams, 1998), based on Yamada's (1982) forest canopy parameterization and includes modification of the TKE and mean momentum equations, modification of radiative transfer, and an anthropogenic heat source. COAMPS is parallelized for both shared memory (OpenMP) and distributed memory (MPI) architecture.

\section{Urban Canopy Parameterization description}

The building effect is parameterized in the horizontal direction in this Urban Canopy Parameterization. In the vertical, we use very high grid resolution to calculate the rooftop effects within each urban canopy. The UCP used is based on Brown and Williams (1998, hereafter BW), which was extended from Yamada's (1982) forest canopy scheme. In this study, additional modifications to the original BW scheme are made to accommodate the model physics in COAMPS and to represent the urban canopy effects in a more consistent way. These modifications include the additions of building drag term in the vertical momentum equation and rooftop surface energy equation, changes in the effects of anthropogenic heat and rooftop in the heat equation, and drag terms in the momentum equations.

The main differences of the urban canopy to the forest canopy are marked in two aspects: 1) the addition of anthropogenic heat source, and 2) further division of the urban canopy into the roof region and the between-building (or so-called street canyon) area 


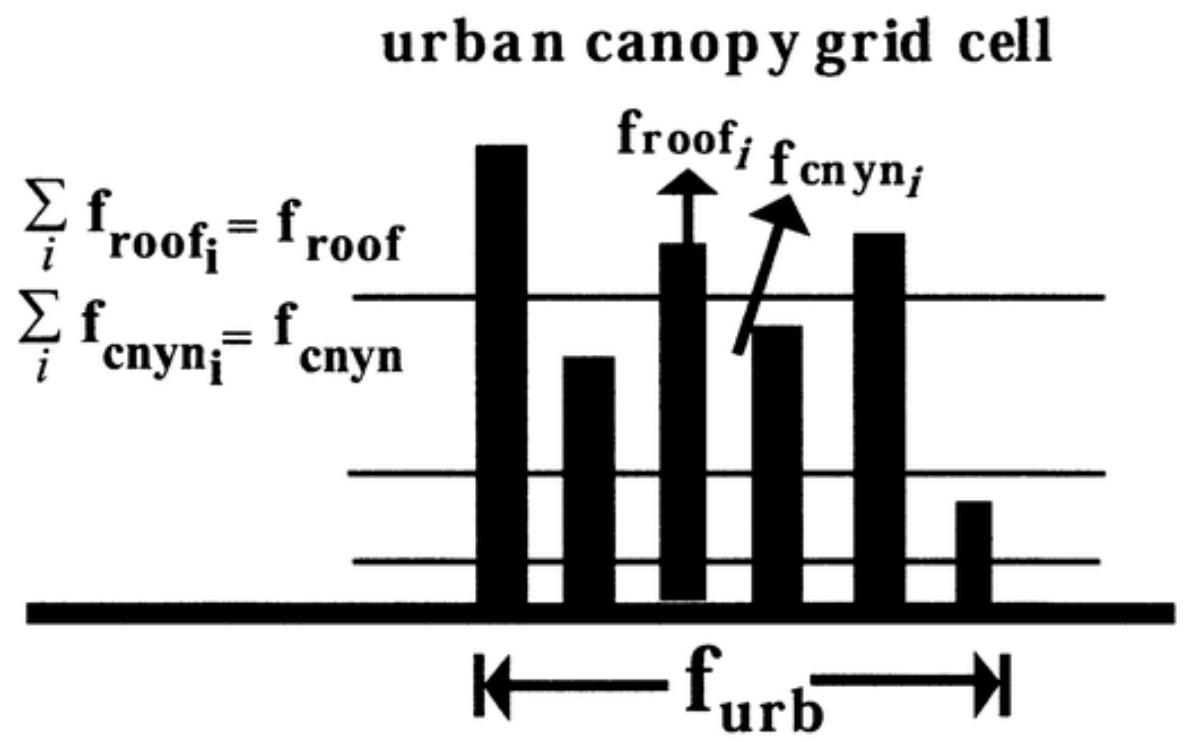

Figure 1. Two-dimensional view of the urban grid configuration in the horizontal and vertical directions. The urban canopy fraction $\left(f_{\text {urb }}\right)$ is further divided into roof fraction $\left(f_{\text {roof }}\right)$ and between-building (or so-called street canyon) fraction $\left(f_{\text {cnyn }}\right)$. The area fraction

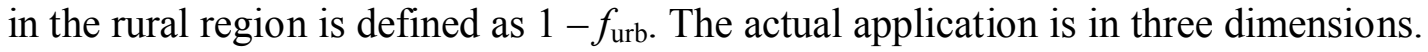

As in the forest canopy, the urban canopy acts as a friction source in the momentum equations:

$\frac{\mathrm{D} U}{\mathrm{D} t}=\cdots-f_{\text {roof }} \times c_{d} \times a(z) \times U \times|U|$,

$\frac{\mathrm{D} V}{\mathrm{D} t}=\cdots-f_{\text {roof }} \times c_{d} \times a(z) \times V \times|V|$,

$\frac{\mathrm{D} W}{\mathrm{D} t}=\cdots-f_{\text {roof }} \times c_{d} \times a(z) \times W \times|W|$,

where $f_{\text {roof }}$ is the horizontal fraction of model grid covered by the building regions of the urban canopy, $c_{d}$ is the drag coefficient of the urban canopy, and $a(z)$ is the building surface area density profile of the urban canopy. The default $\mathrm{a}(\mathrm{z})$ profile is linear as shown in Figure 2. 


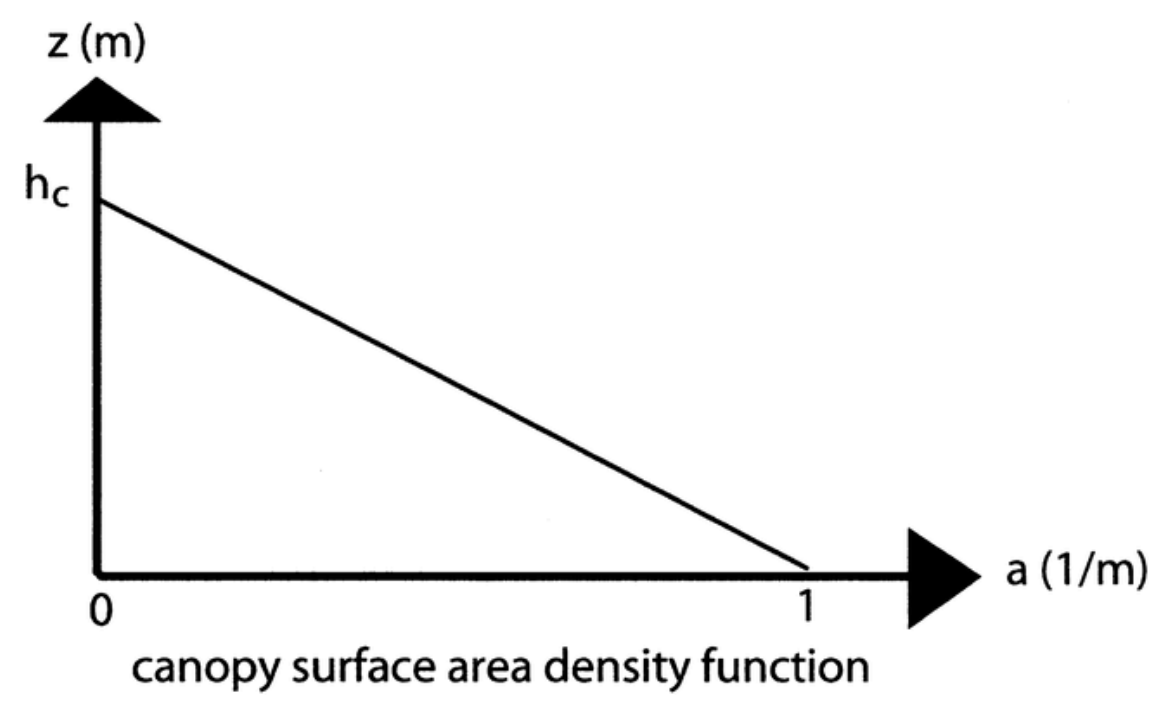

Figure 2. The building surface area density profile of the urban canopy in this study is assumed to be linearly decreased from the surface to the top of the highest building (i.e., the height of the urban canopy, $h_{c}$ ).

The urban canopy is treated as a source of turbulence production to account for generation in the turbulence kinetic energy (TKE) equation,

$$
\begin{aligned}
\frac{\mathrm{D}(\mathrm{TKE})}{\mathrm{D} t}= & \cdots+f_{\text {roof }} \times c_{d} \times a(z) \times\left(|U|^{3}\right. \\
& \left.+|V|^{3}+|W|^{3}\right) .
\end{aligned}
$$

Using $f_{\text {roof }}$ in the TKE and momentum equations rather than $f_{\text {urb }}$ as in the BW scheme creates more dependence of urban drag on the building area fraction rather than on the street canyon fraction.

The impacts of the urban canopy on the potential temperature equation is expressed by

$$
\begin{aligned}
\frac{\mathrm{D} \theta}{\mathrm{D} t}= & \cdots+\frac{1}{\pi \times \rho \times c_{p}} \times\left\{\left(1-f_{\text {urb }}\right) \times \frac{\partial R_{N}}{\partial z}+f_{\text {urb }}\right. \\
& \times \frac{\partial q_{\mathrm{urb}}}{\partial z}+\left(1+\frac{1}{B}\right)^{-1} \times\left[\left(f_{\text {urb }}-f_{\text {roof }}\right) \frac{\partial R_{\mathrm{Nc}}}{\partial z}\right. \\
& \left.\left.+f_{\text {roof }} \times b(z) \frac{\rho \times c_{p} \times \Delta q_{\text {roof }}}{C_{\text {roof }}}\right]\right\},
\end{aligned}
$$


where $R_{N}$ and $R_{\mathrm{Nc}}$ are the net downward radiative longwave plus shortwave (LW $+\mathrm{SW}$ ) fluxes in the rural and street canyon regions of the urban canopy, respectively, $\pi$ is nondimensional pressure, $\rho$ is air density, $c_{p}$ is specific heat of dry air at constant pressure, $B$ is Bowen ratio of the urban canopy, $C_{\text {roof }}$ is heat capacity of the roof, and $b\left(z_{k}\right)$ is the normalized function of roof surface area density function, defined as $\left[a\left(z_{k}\right) \times \mathrm{d} z_{k} / \Sigma_{k}\right.$ $a\left(z_{k}\right) \times \mathrm{d} z_{k}$ ], where $\mathrm{d} z_{k}$ is the vertical grid depth within the urban canopy. The normalized function, $b(z)$ is used to prevent the UCP from over predicting the rooftop effects of nighttime warming and daytime cooling, respectively.

Equation (5) contains four terms describing the physics processes: 1) the radiative heating/cooling term in the rural region, 2) the anthropogenic heating term in the urban region, 3) the radiative heating/cooling term in the street canyon region, and 4) the rooftop heating/cooling term in the urban region with buildings.

The net radiative flux within the street canyon region is defined as

$$
R_{\mathrm{Nc}}(z)=R_{h}^{\text {net } \downarrow} \times \exp [-k \times L(z)]
$$

where $R^{\text {net }}{ }_{h}$ is the net downward total radiative flux at the top of the urban canopy, $k$ a user-specified extinction coefficient, and $L(z)$ the cumulative index of building surface area determined by

$$
L(z)=\int_{z}^{h_{c}} a\left(z^{\prime}\right) \times \mathrm{d} z^{\prime},
$$

where $h_{c}$ is the height of the urban canopy top.

The heat flux change of the rooftop surface at each level of model grids within the urban canopy is calculated by

$$
\begin{aligned}
\Delta q_{\text {roof }}= & R_{\text {SW }}^{\downarrow} \times(1-\alpha)+\varepsilon \times\left(R_{\text {LW }}^{\downarrow}-\sigma T^{4}\right)-\rho \times c_{p} \\
& \times c_{\text {d_roof }} \times|\mathbf{V}| \times\left(T_{\text {roof }}-T\right),
\end{aligned}
$$

where $R_{\text {SW }}^{\downarrow}$ and $R_{\text {LW }}^{\downarrow}$ are the downward SW and LW radiative fluxes at the rooftop surface, $\alpha$ is roof albedo, $e$ is roof emissivity, $c_{\mathrm{d}_{-} \text {roof }}$ is drag coefficient of roof surface, and $|\mathbf{V}|$ and $T$ are ambient wind velocity and temperature. Here $T_{\text {roof }}$ is determined by the rooftop surface energy equation, $\left({ }^{*} T_{\text {roof }} /{ }^{*} t\right)=\left(\Delta q_{\text {roof }} / C_{\text {roof }}\right)$.

Equation (8) is simplified in BW's scheme by assuming that the rooftop is infinitely thin and that all radiation absorbed by the roof is immediately reemitted as LW radiation at the air temperature; that is, the roof has no heat storage capacity. The addition of the rooftop surface energy equation enables the modified UCP to exhibit a more reasonable 
diurnal cycle of the heat island effect (Chin et al. 2000), which produces the nighttime warming with the maximum near-sunrise and daytime cooling as observed in many field experiments (Garstang et al 1975.;Oke, 1982;Bornstein, 1987). This modified UCP also results in stronger nighttime warming/daytime cooling with increasing roof fraction. Because of the larger heat capacity of rooftop, a larger roof fraction causes a greater time lag of the temperature rise after sunrise.

The impact of the urban canopy on the surface radiation budget is treated differently from its forest counterpart by assuming that the heat within the building portion of the urban canopy is released directly into the air aloft. Therefore, the anthropogenic and rooftop heating terms in the roof region are assumed to have no impact on the surface net total radiative flux $\left(R_{\mathrm{NG}}\right)$,

$$
\begin{aligned}
R_{\mathrm{N}_{\mathrm{G}}}= & \left(1-f_{\mathrm{urb}}\right) \times\left(R_{\mathrm{SW}}^{\mathrm{net} \downarrow}-R_{\mathrm{LW}}^{\mathrm{net} \downarrow}\right)_{G}+f_{\text {cnyn }} \\
& \times\left[R_{\mathrm{N}_{\mathrm{c}}}(0)\right]_{G},
\end{aligned}
$$

and the surface energy equation,

$$
\frac{\partial T_{G}}{\partial t}=R_{\mathrm{N}_{G}}-H_{G}-L_{G}-S_{G},
$$

where $T_{G}, H_{G}, L_{G}$, and $S_{G}$ are surface temperature, sensible heat flux, latent heat flux, and soil-layer heat flux, respectively.

\section{Urban canopy parameters}

A major challenge for using an $\mathrm{UCP}$ in mesoscale models is to determine appropriate input parameters. For this purpose, different resolutions of the USGS land-use datasets are used in conjunction with the available urban infrastructure and urban surface properties to provide the required input information for the UCP. These land-use data, Land Use Land Cover (LULC) and National Land Cover Data (NLCD), have a resolution of approximately 200 and $30 \mathrm{~m}$, respectively. The 200-m dataset (LULC) has a total of 37 land surface categories, including seven urban categories. The 30-m dataset (NLCD) has 21 land-use categories in total, but with only three urban categories, covering highand low-density residential, industrial, and commercial areas. Therefore, the primary urbanization categories are not represented in the high-resolution $(30 \mathrm{~m})$ land-use dataset 
Tables 1 and 2 present the subset of the two land-use data bases that include urban areas. These values have been derived from satellite imagery for Salt Lake City and should be examined and modified accordingly as new data are obtained and more objective techniques are developed. For a complete listing of the USGS land-use categories, see the tables in Chin et al., (2005)

TABLE 1. Description of land-use categories based on the 200-m resolution of USGS data and physical parameters. Note that $\mathbf{f}$ _urban is always set to one for a land-use category, but a typical mesoscale grid cell will contain several land-use categories, and in general, f_urban will be less than 1.

\begin{tabular}{|l|l|l|l|l|}
\hline USGS LULC & f_urban & f_roof & h_urban $(\mathrm{m})$ & q_urban $\left(\mathrm{Wm}^{-2}\right)$ \\
\hline Residential & 1.0 & 0.33 & 10 & 20 \\
\hline Commercial Service & 1.0 & 0.25 & 25 & 25 \\
\hline Industrial & 1.0 & 0.2 & 15 & 15 \\
\hline Communication & 1.0 & 0.2 & 15 & 15 \\
\hline Industrial-Commercial & 1.0 & 0.25 & 25 & 25 \\
\hline Mixed Urban & 1.0 & 0.25 & 20 & 20 \\
\hline Other Urban & 1.0 & 0.5 & 50 & 50 \\
\hline
\end{tabular}

TABLE 2. Description of land-use categories based on the 30-m resolution of USGS data and physical parameters.

\begin{tabular}{|l|l|l|l|l|}
\hline USGS NLCD & f_urban & f_roof & h_urban $(\mathrm{m})$ & q_urban $\left(\mathrm{Wm}^{-2}\right)$ \\
\hline Low-density residential & 1.0 & 0.33 & 10 & 20 \\
\hline High-density residential & 1.0 & 0.33 & 20 & 25 \\
\hline Commercial-Industrial & 1.0 & 0.33 & 20 & 25 \\
\hline
\end{tabular}

Unlike the urban surface properties, the urban infrastructure properties for a given land-use category (e.g., building height and anthropogenic heating) may greatly vary from city to city. Urban infrastructure properties shown in are based on the satellite aerial photo to estimate the urban and roof fraction information for the Salt Lake Valley. The urban canopy height and anthropogenic heating are estimated from actual building height and population information. Then, the urban infrastructure properties at the mesoscale grid can be derived in the same way as the surface properties via a table conversion approach. Further application of these urban infrastructure properties needs proper adjustment to fit the actual application for other geographic locations.

The derived urban infrastructure properties are assumed to be time-invariant parameters while the urban surface properties have seasonal variation based on a sine function from the winter and summer maximum or minimum values. Therefore, this table conversion approach provides an initial estimate for a database for the urban properties, which can be applied to other geographic locations. 
The urban variables are included with other physics options in the coamps.nml namelist. The urban variables are described in table 3. See the COAMPS users manual for a full description of the namelists. The subroutines that have been modified in the COAMPS source code are listed in Table 4, along with a brief description of the function of those routines. A complete listing of the coamps.nml namelist is included in an Appendix.

Table3: The urban namelist variable which should be added to coamps.nml for using the urban option.

\begin{tabular}{|l|l|l|}
\hline Variable & Default & description \\
\hline lurban & .false. & $\begin{array}{l}\text { Determine whether to perform urban } \\
\text { calculations. }\end{array}$ \\
\hline lusgs & .false. & $\begin{array}{l}\text { Read urban parameters from land-use file if } \\
\text { true. Otherwise, perform an idealized } \\
\text { distribution for urban parameters. }\end{array}$ \\
\hline lusgs_urban & .false. & Modify the drag term for buildings. \\
\hline lusgs_sfc & .false. & $\begin{array}{l}\text { If ground wetness, surface albedo and } \\
\text { roughness length are not defined, set them to } \\
\text { the values retrieved from the land-use file. }\end{array}$ \\
\hline
\end{tabular}

The COAMPS variables affected directly by reading in variables from the USGS landuse tables are z0 (roughness length), gwet (ground wetness) and albed (albedo). For simulating an idealized urban, set lurban to .true., and lusgs to .false. For an idealized distribution of urban parameters, the variables described in Tables 1 and 2 must be defined in subroutine urban, creating the desired urban distribution.

Table 4. The COAMPS subroutines in which changes to the code have been made described in Table 4.

\begin{tabular}{|l|l|}
\hline Subroutine & Effect \\
\hline afore & Includes effect on TKE budget \\
\hline ainit & Initializes the dynamic fields in COAMPS \\
\hline amodel & Controls calls to physics modules. \\
\hline arhsu & Calculates the forcing function for the u-momentum equation \\
\hline arhsv & Calculates the forcing function for the v-momentum equation \\
\hline arhsw & Calculates the forcing function for the w-momentum equation \\
\hline coami & Sets up the static parameters, including the urban parameters \\
\hline coamm & Controls the time integration \\
\hline dfalts & Sets up input/output file names and units in those files \\
\hline memm & Allocates memory for urban arrays \\
\hline sfcenr & Computes the surface energy balance, including for urban area \\
\hline sfcflx & Computes surface fluxes, including for urban area. \\
\hline urban & Initializes urban parameters and calls to urban data base \\
\hline
\end{tabular}




\section{References:}

Bornstein, R. A., 1987: Mean diurnal circulation and thermodynamic evolution of urban boundary layer. Modeling the Urban Boundary Layer, M. L. Kramer, Ed., Amer. Meteor. Soc., 53-93.

Brown, M. J., and M. Williams, 1998: An urban canopy parameterization for mesoscale meteorological models. Proc. Second Symp. on the Urban Environment, Albuquerque, NM, Amer. Meteor. Soc., 144-147.

Chin, H.-N. S. and M. J. Leach, G. A. Sugiyama, J. M. Leone Jr., H. Walker, J.S.

Nasstrom and M. J. Brown, 2005: Evaluation of an Urban Canopy Parameterization in a Mesoscale Model using VTMX and URBAN 2000 Data., Mo. Wea. Rev, 133, 2043-2068.

COAMPS Version 3 Model Description: General Theory and Equations, Naval Research Laboratory, Marine Meteorology Division, Moneterey, California, NRL/PU/7500 — 03 448, May 2003.

Doyle, J.D. 1997, The Influence of Mesoscale Orography on a Coastal Jet and Rainband, Mo. Wea. Rev.125:1465-1488.

Garstang, M., P. D. Tyson, and G. D. Emmitt, 1975: The structure of heat islands. Rev. Geophys. Space Phys., 13, 139-165.

Hodur, R., 1997: The Naval Research Laboratory's Coupled Ocean-Atmospheric Mesoscale Prediction System (COAMPS). Mon. Wea. Rev., 125, 1414-1430.

Oke, T. R., 1982: The energetic basis of the urban heat island. Quart. J. Roy. Meteor. Soc., 108, 1-24.

Yamada, T., 1982: A numerical model study of turbulent airflow in and above a forest canopy. J. Meteor. Soc. Japan., 60, 439-454. 


\section{Appendix}

This appendix includes a complete coamps.nml namelist file. The urban parameters are bold. For a complete description of the namelist and all of the variables defined, see the COAMPS Version 3 Model Description.

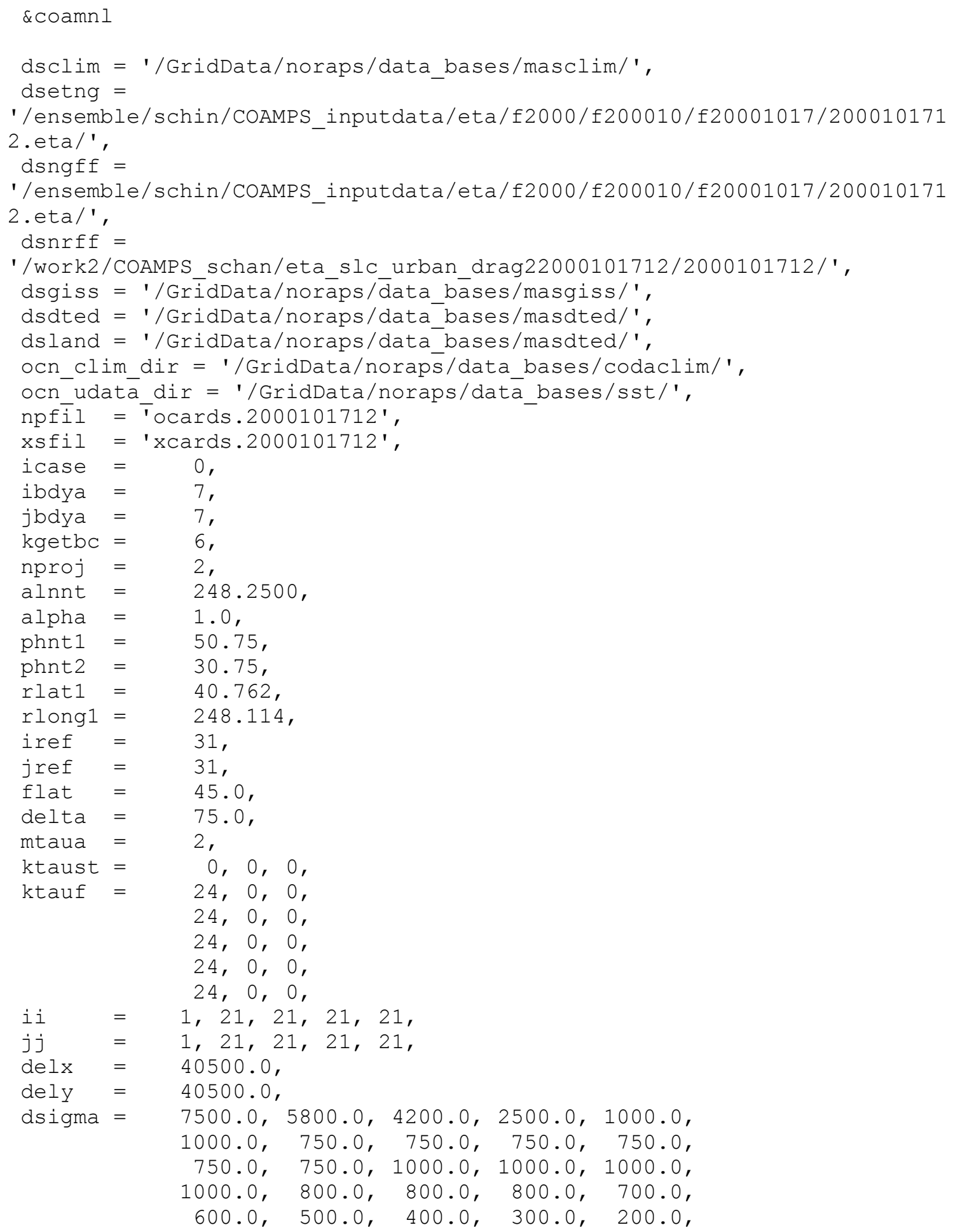




$$
\begin{aligned}
& 120.0, \quad 70.0, \quad 42.0, \quad 24.0, \quad 14.0, \\
& 10.0, \quad 6.0, \quad 4.0, \quad 4.0, \quad 4.0, \\
& \mathrm{pr}=50.0, \quad 100.0,150.0 \text {, } \\
& 200.0, \quad 250.0, \quad 300.0,400.0, \quad 500.0, \quad 700.0,800.0,
\end{aligned}
$$

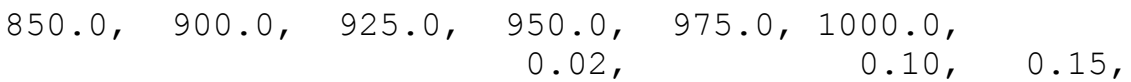

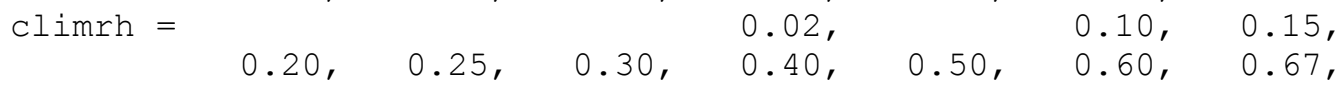

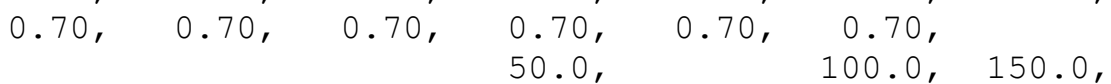

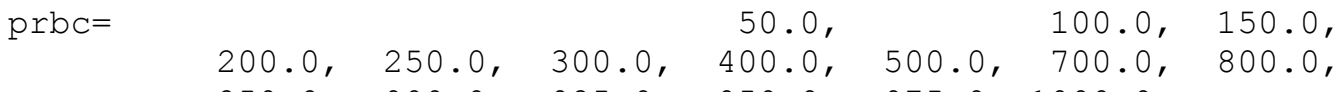

$$
\begin{aligned}
& \text { ipsnd }=1 \text {, } \\
& 850.0,900.0,925.0,950.0,975.0,1000.0 \text {, } \\
& \text { iqsind }=3 \text {, } \\
& \text { itsnd }=1 \text {, } \\
& \text { iuvsnd }=2 \text {, } \\
& \text { tsnd }=293.1,286.5,281.6,277.8,274.8,273.2,271.7,273.7,272.9, \\
& 272.2 \text {, } \\
& 239.4, \\
& 271.5,271.5,270.3,268.8,264.9,259.6,253.9,252.2,246.7, \\
& 230.1,221.4,218.8,219.3,211.0,219.1,225.4,234.9,245.4, \\
& 270.9, \\
& 257.0,226.7, \\
& \text { qsnd }=8.220,6.310,5.320,4.330,4.311,4.070,3.760,3.650,3.450 \text {, } \\
& 3.140,3.000,2.440,2.280,1.380,0.584,0.360,0.170,0.029 \text {, } \\
& 0.034,0.052,0.016,0.008,0.007,0.003,0.002,0.006,0.017 \text {, } \\
& 0.026,0.017,0.010,0.005,0.003 \text {, } \\
& \text { psnd }=1000 ., 975 ., 950 ., 925 ., 900 ., 875 ., 850 ., 825 ., 800 ., 775 . \text {, }
\end{aligned}
$$




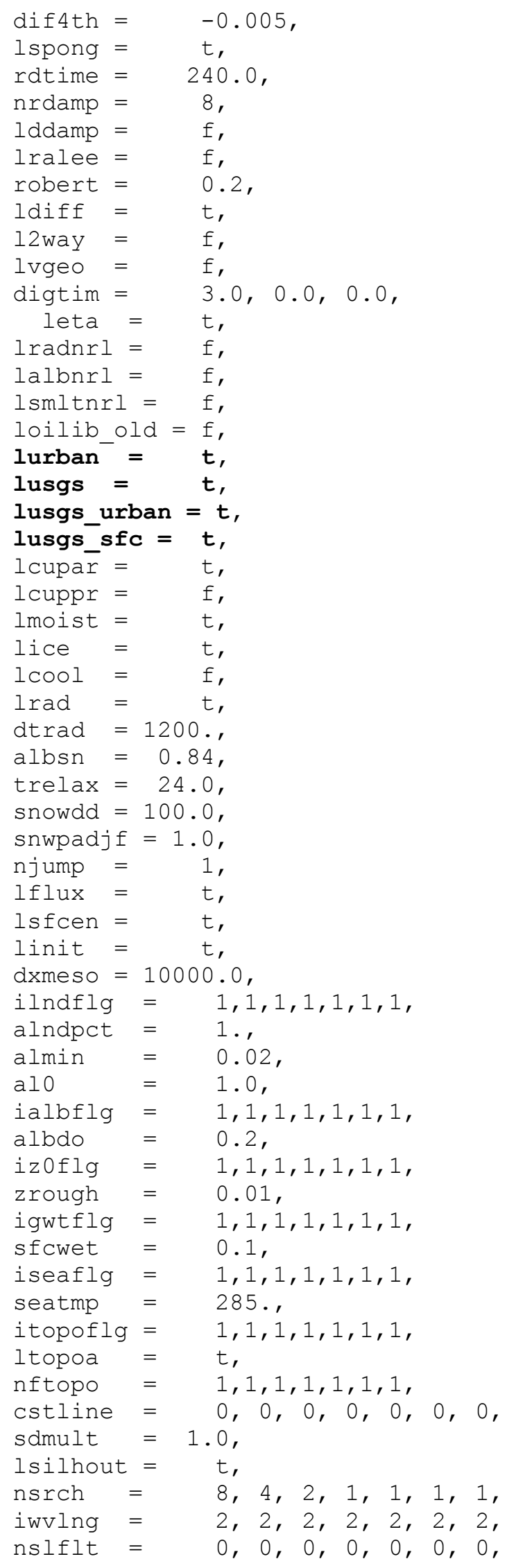




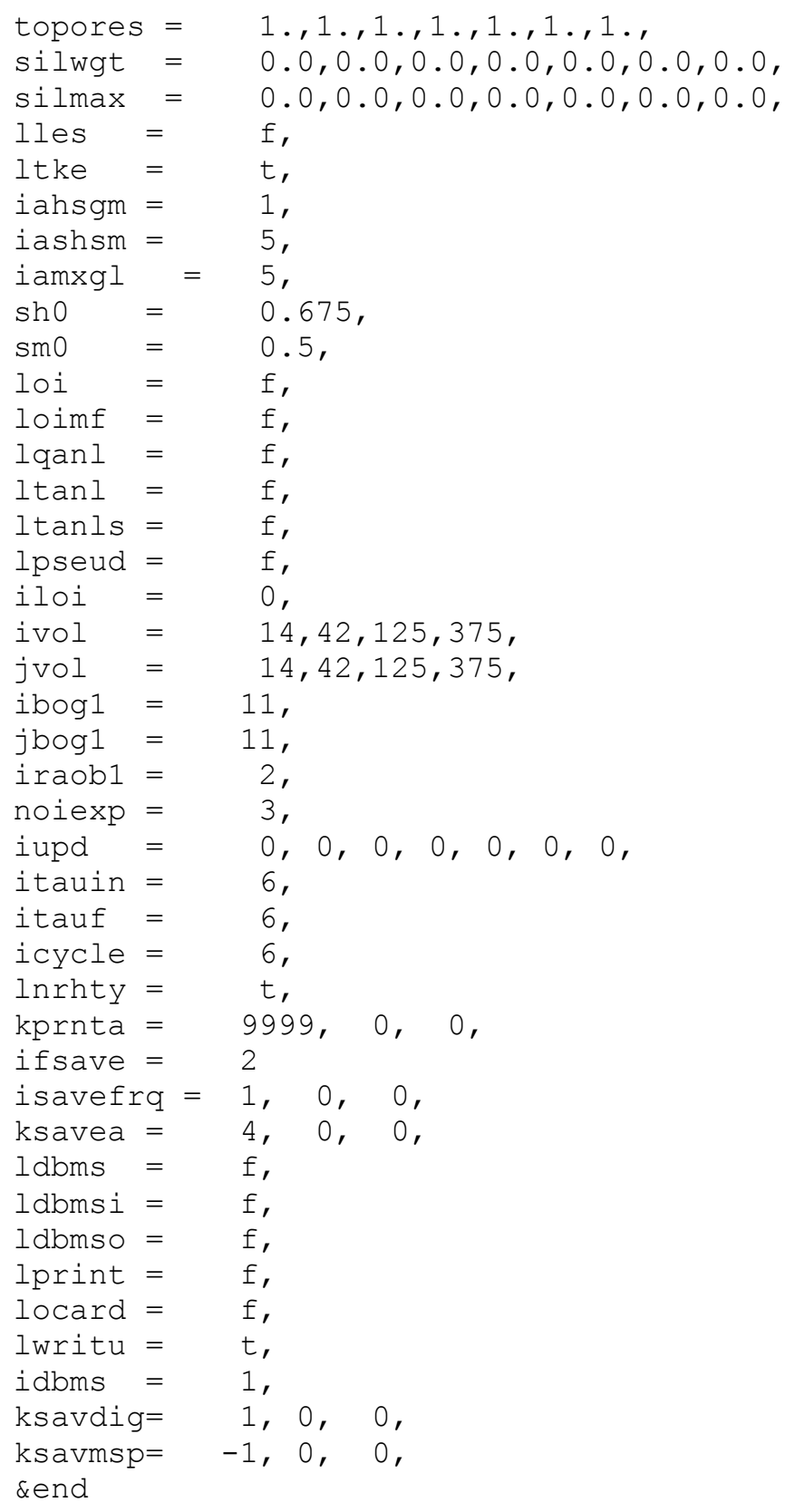

